\title{
Dependence of Cognitive Processes from the Individual Psychophysiological Characteristics of Upper-School Students of a Special Lyceum
}

\author{
Viacheslav Ivanovich Hasnulin, Tatiana Ivanovna Riabichenko, \\ Anna Vlfdimirovna V. Hasnulina, Galina Aleksandrovna Skosyreva, \\ Yulia Nikolaevna Patrusheva
}

Scientific Center of Clinical and Experimental Medicine of the Russian Academy of Medical Sciences, Siberian Branch, Novosibirsk, Russia

Email: narinebalance@ngs.ru

Received 6 December 2013; revised 6 January 2014; accepted 13 January 2014

Copyright (C) 2014 by authors and Scientific Research Publishing Inc.

This work is licensed under the Creative Commons Attribution International License (CC BY).

http://creativecommons.org/licenses/by/4.0/

(c) (i) Open Access

\begin{abstract}
The enrichment by highly information load of the school educational process, which leads in severe environment to psycho-emotional stress, confirms the necessity of studying the psycho-emotional and physiological stability of the senior schoolboys to information educational stress in rugged climate/geographic regions of Siberia. Observed were the 110 teenagers, the inhabitants of Novosibirsk, the students of $9^{\text {th }}-1^{\text {th }}$ classes of the special lycée. Clinical, psychological, psychophysiological, biochemical and hormonal methods of observation were used. It was shown that efficiency of the modern information-enriched educational process defines a complex of individual adaptive characteristics of an organism, including lateral phenotype of the prevalence of cerebral hemispheres, the stability of psychophysiological response, minimization of painful reaction to sharp changes of the factors of nature-meteosensitivity, and also the belonging to chronotypes (morning or evening). These features form the basis of stability of the young organism to the educational information stress and to the action of rugged climate-meteorological and biorhytmological factors, aggravating this stress.
\end{abstract}

\section{Keywords}

Psycho-Emotional Stress, Meteosensitivity, Functions of Hemispheres of Brain, Informational Educational Stress, Efficiency of Education Process 


\section{Actuality}

The modern educational process full of high-level informational load often becomes a serious stress factor for the senior students of special schools. This factor is not only risk factor of deterioration of health, but also may be a reason of the worsening educational process, bad results of learning as a whole and the decreasing resistance to stress [1]-[4]. At the same time not every pupil is bad in the learning progress of intensive school program. Thereat the study of psycho-physiological characteristics of senior pupils is of primary importance. The psycho-physiological characteristics are of high effectiveness in school educational process that is full of information.

The aim of this research is to study the peculiarities of psycho-emotional and physiological stability of senior pupils to informational educational stress in unfavorable geographic-climatic Siberian regions.

\section{Materials and Methods}

Studied are 110 children of adolescent age living in Novosibirsk and learning at the 9th - 10th classes in the Lyceum of the State Technical University, Novosibirsk. The study was done by the written approbation and under permission of the ethical committee in compliance with the standards of the Helsinki declaration in 1975 and its further revision in 1983. The definition of psycho-physiological stress characteristics was performed using the complex of computer standard tests. The intensity of disadaptive disorder display and psycho-emotional exertion (PEE) were done using the methods "question - answer" of the computer program "Screenmed" (license No.970035, 1997.09.21 Scientific Center of Clinical and Experimental Medicine of the Russian Academy of Medical Sciences, Siberian Branch.

The content of stress hormone (cortisol) in blood serum was identified by radioimmunoassay technique with use of commercial sets. Biochemical parameters (general cholesterol, total fraction of lipoprotein of low and very low density, triglycerides, glucose and uric acid) were identified with the help of standardized set at biochemical analyzer. Blood sampling for biochemical analysis was executed at the same morning hours.

The statistical data processing was performed with help of standard statistical package of programs STATISTICA (StatSoft, USA), the version 7.0. The quantitative data is given in the form of average indices (M) and of the standard mistake of average index (m) at the regular distribution of indices. The statistical importance of differences was identified by paired Student's-t-criteria for independent sampling. The threshold level of statistical importance was taken at the criteria value $p<0.05$. The correlative analysis was performed by the Peerson's method.

\section{Results}

Among examined senior pupils 36.5\% have shown high results in learning; 24.4\%—average results in learning; $39 \%$ - satisfactory and low grades. It was found that it's possible to form three main groups in compliance with the pupils' progress in learning different school subjects. In one of the groups were prevailed the high grades in physics, algebra, geometry and chemistry were (1st group- “physicists"). In the second group the highest grades were obtained in humanitarian subjects (2nd group- "lyricists" or "humanists"). The third group was formed by pupils with similar grades in all the subjects. Only $15.8 \%$ of all senior pupils were included in the "physicists" group. The average grade in the progress of learning in compliance with the year results in this group was $4.2 \pm$ 0.04 points in the second group $-3.6 \pm 0.04$ points $(\mathrm{p}<0.001)$.

What is the difference of these three groups-one from another-in psycho-physiological characteristics? The intellectual efficiency of "Physicists' is more higher (9.6 \pm 0.2 points) compared to "Humanists" $(9.4 \pm 0.2$ points). The pupils of the first group have shown the lower level of psycho-emotional tension (10.8 \pm 0.6 standard units), while the psycho-emotional tension of the pupils in second group was at higher level (13.6 \pm 0.7 standard unit) ( $\mathrm{p}$ 0.003). The psychological discomfort (by 42.5\%) and aggressiveness (by 70.1\%) at "humanists" were higher than the same at "physicists". Also, "humanists" have shown the higher anxiety level (2.68 \pm 0.08 points), whereas at "physicists" it was $1.84 \pm 0.12$ points, $\mathrm{p}<0.001)$. Higher stress level in the second group is also confirmed by cortisol concentration in the blood ("humanists" $-652.8 \pm 25.1 \mathrm{nmol} / \mathrm{l}$, "physicists" $-598.3 \pm 16.7 \mathrm{nmol} / \mathrm{l}$ ). Besides, the pupils of second group had higher dysadaptation level ("humanists" $-41.8 \pm 3.0$; "physicists" $-38.8 \pm 3.8$ ). The pupils of the second group were noted for less precise sensation of time intervals (individual minute for "humanists" was $55.7 \pm 1.0 \mathrm{sec}$, while for "physicists" $59.0 \pm 1.0$ 
sec; $\mathrm{p}<0.05$ ). Meanwhile the second group had demonstrated lower stability indices (by $12.6 \%$ ) to hypoxic load during the tests for exhalation at breath-holding.

There are numerous data which confirm that the differences between "physicists" and "poets" are determined by genephenotypical domination of the functions of left-brain hemisphere over the right-brain hemisphere [1] [5] [6] - it helped us to compare the psycho-physiological indices of examined pupils depending on functional activity of right-brain and left-brain hemispheres. It was found that intellectual capacity of the left-hemisphered pupils with high functions of the right-brain hemisphere was higher (10.1 \pm 0.3 points) than the intellectual capacity of the right-hemisphered pupils $(9.1 \pm 0.2$ points; $p<0.01)$. Psychological discomfort indices were lower (at left-hemisphered pupils- $0.2 \pm 0.02$, right-hemisphered pupils $0.5 \pm 0.03 ; \mathrm{p}<0.001$ ); conflict degree (at lefthemisphered pupils $-0.14 \pm 0.01$ points, right-hemisphered pupils $-0.50 \pm 0.02 ; \mathrm{p}<0.001$ ); aggressiveness level (at left-hemisphered pupils $-0.5 \pm 0.01$, right-hemisphered pupils $-0.8 \pm 0.02 ; \mathrm{p}<0.001$ ); psycho-emotional tension level (at left-hemisphered pupils-10.9 \pm 0.3 , right-hemisphered pupils-12.7 $\pm 0.4 ; \mathrm{p}<0.003$ ); concentration of cortisol in blood (at left-hemisphered pupils $-608.7 \pm 17.3 \mathrm{nmol} / \mathrm{l}$, right-hemisphered pupils$687.7 \pm 23.1 \mathrm{nmol} / \mathrm{l} ; \mathrm{p}<0.01$ ). The average progress grade was by $5.3 \%$ lower among left-hemisphered pupils than at right-hemisphered ones. At the same time the average progress grade at "physics" was by $7.7 \%$ higher at the left-hemisphered pupils than at right-hemisphered ones.

The data given in the Table 1 confirm the higher importance of functional activity of the right hemisphere of brain in the stability of pupils to psycho-emotional stress, thus to more efficiency of educational process.

As appears from the data of Table 1 the higher speed of the simple sensomotoric reactions of right hand (high activity of the left hemisphere of brain) - promotes the more stability of an organism to psycho-emotional stress. It leads to higher progress of pupils possessing the high activity of the left hemisphere of brain.

The another mechanism of stabilizing to the informational educational stress, fixed individually to all the examined pupils, is the chronotype. There are lots of data when one may read about how cognitive processes depend on biorythmic organization of the functioning of organism [7]-[10]. It was found that the level of psychoemotional stress of the pupils of the morning chronotype was by $12.7 \%$ lower than the same at the evening chronotype. At the same time, the stress level shown by cortisol concentration in the blood of pupils of morning chronotype was by $17.2 \%$ lower than of the pupils of evening chronotype. Degree of dysadaptation at the pupils of morning chronotype was by $29 \%$ lower compared to the evening chronotype's pupils. An average progress grade among the evening chronotype's pupils was by 3\% lower than at the morning chronotype's pupils.

The results of our research have also shown: the degree of informational educational stress of pupils depends on their personal stability against unfavorable climatic-meteorological factors defined by level of painful meteosensitivity. Vallah F.L. [11] connects the educational progress at school with meteoreaction of pupils. Our data have shown that the psycho-emotional tension on condition of higher stability to the unfavorable climaticmeteorological conditions was by $22.3 \%$ lower, than at strong response to the change of meteofactors. Besides, larger informational educational stress among pupils of high meteosensitivity was confirmed by high cortisol level in their blood (by 15.8\%). The speed of restoration reactions among the people with low meteosensitivity was by $14.7 \%$ higher than the same among people with high meteosensitivity. At people with high meteosensitivity were found: lower level of adaptive reserves (high meteosensitivity $-7.4 \pm 0.6$ points; low meteosensitivity - 83.6 \pm 0.9 points; $p<0.001$ ), as well as higher degree of desynchronization's manifestations (high meteosensitivity $-5.0 \pm 0.4$ points; low meteosensitivity-3.3 \pm 0.3 points; $\mathrm{p}<0.003$ ).

Table 1. Level of psycho-emotional stress and the average progress of pupils of the senior classes depending on functional activity of hemispheres of brain. The level is measured by the speed of simple sensomotoric reactions of right and left hands.

\begin{tabular}{|c|c|c|c|}
\hline \multirow{2}{*}{ Factors } & \multicolumn{2}{|c|}{ Speed of sensomotoric reaction } & \multirow{2}{*}{ Statistical validity $(\mathrm{p})$} \\
\hline & High $\mathrm{n}=31$ & Lower $n=43$ & \\
\hline Time period of reaction of right hand (msec) & $187.5 \pm 2.2$ & $234.6 \pm 2.3$ & $<0.001$ \\
\hline Time period of reaction of left hand (msec) & $191.0 \pm 3.3$ & $224.9 \pm 2.7$ & $<0.001$ \\
\hline Level of psycho-emotional stress (ref.unit) & $10.4 \pm 0.5$ & $13.0 \pm 0.6$ & $<0.003$ \\
\hline Mean score of progress & $3.9 \pm 0.1$ & $3.6 \pm 0.08$ & $<0.05$ \\
\hline
\end{tabular}




\section{Discussion}

The research results obtained permit us to state that the success of informative-rich school-learning process in a special school depends on the row of personal psychophysiological features of body functioning which are specified by genephenotypical mechanisms. Revealed is the fact that the capabilities to perform the effective learning process depend on the high functional activity of the brain hemispheres where left-hemisphere of brain dominates. The left-hemisphere of brain is responsible for verbalization of information and the aptitude of person to the "exact" sciences. At the same time the certain role in the efficiency of learning is the ability of an organism of teenager to sustain without problems the sharp weather changes of Siberia. This adaptive stability to negative disturbances of nature is defined by low level of meteosensitivity.

The another mechanism of high educational effectiveness is the stability to the rhythms of learning that do not coincide with the rhythms of daylight. Examined pupils in the conditions of all-year summer time existing in Russia begin to study at $6.30 \mathrm{a} . \mathrm{m}$. according to the standard (zone) time. The more probably is it the reason of higher educational progress of morning chronotype's pupils and of lower informational stress level.

\section{Conclusion}

The results of our work allow to say: the efficiency of educational process of pupils of a special lycée depends on individual genophenotypical psycho-physiological features (stability to psycho-emotional stress, prevalence of left hemisphere of brain, low meteosensitivity, chronotype "morning”), which provides the stability of a human both to educational information stress and to the action of climate-meteorological and bio-rhytmological factors of environment, aggravating this stress. The obtained data demand the further studying of the psycho-physiological mechanisms of adaptation depending on the stability of a young organism to educational information stress at the everyday uncomfortable climate-geographic conditions of environment. It's necessary to develop the requirements to the job orientation of pupils, as well as to work out the methods to prevent the formation and progressing of information stress.

\section{References}

[1] Aghadzanov, V.R. (2002) Modern Ideas of Functional Asymmetry of Human Adaptation to the Environment. Medico-Biological and Psycho-Pedagogical Adaptation and Socialization: Proceedings of the All-Russia Roundtable. Scientific\& practical conf.-Volgograd: Volgograd State University, Publishing House, 73-74 (Russian).

[2] Bezrukich, M.M. (2006) Physiological Bases of the Effectiveness of the Educational Process. Lectures 1-4. Moscow Pedagogical University “Pervoje sentjabrja”, 44 pages (Russian).

[3] Bodrov, V.A., Oboznov, A.A. and Turzin, P.S. (1998) Informational Stress in Operation Activity. Journal of Psychology, 19, 38-54 (Russian).

[4] Glozah, F.N. (2013) Effects of Academic Stress and Perceived Social Support on the Psychological Wellbeing of Adolescents in Ghana. Open Journal of Medical Psychology, 2, 143-150. http://dx.doi.org/10.4236/ojmp.2013.24022

[5] Bragina, I.I. and Dobrokhotova, T.A. (1988) The Functional Asymmetry of the Human. Moscow: Medicine, 288 pages (Russian).

[6] Leutin, V.P. and Nikolaeva, E.I. (2005) Functional Asymmetry of Brain, Myths and Reality. St.Petersburg: Rech. 368 p. (Russian).

[7] Putilov, A.A. (2003) “Owls”, "Larks” at al. -Novosibirsk -M.: "Sovershenstvo”, 608 pages (Russian).

[8] Stepanova, S.I. (2004) Circadian Variation of Mental Health. Russian Journal of Physiology, 90, 22-26 (Russian).

[9] Waeckerle, J.F. (1994) Circadian Rhythm, Shift Work, and Emergence Physicians. Annals of Emergency Medicine, 24, 928-934.

[10] Thomas, E.A.C. and Weaver, W.B. (1975) Cognitive Processing and Time Perception. Perception and Psychophysics, 17, 363-367.

[11] Valakh, F.L., Aleutskaya, I.N. and Pyatkov, A.V. (1999) Meteolability in Capability to Learning of the Secondary School Pupils. In: Ecology of Education: Current Problems. The 1st Issue. Arkhangelsk, Publishing House of the Pomorsky State University by Lomonosov MSU, 306-313 (Russian). 